\title{
Correction to: Family Therapy with Involuntary Clients. The Therapeutic Alliance as a Major Key to Therapy Success
}

\author{
Ana Paula Relvas and Luciana Sotero
}

\section{Correction to:}

Chapter 13 in: R. Pereira, J. L. Linares (eds.), Clinical Interventions in Systemic Couple and Family Therapy, European Family Therapy Association Series, https://doi.org/10.1007/978-3-319-78521-9_13

In chapter 13, the affiliation of the co-author Luciana Sotero, along with Ana Paula Relvas was incompletely published in the original version of the book. It only mentioned the Faculty of Psychology and Education Sciences. Both of them are also researchers at the Centre for Social Studies of the Coimbra University (CES).

This has been updated in this version of the book.

The updated online version of this chapter can be found at https://doi.org/10.1007/978-3-319-78521-9_13 